\title{
An under-diagnosed geriatric syndrome: sleep disorders among older adults.
}

\author{
Asli Tufan ${ }^{1}$, Birkan Ilhan², Gulistan Bahat ${ }^{2}$, Mehmet Akif Karan²
}

1. Marmara University Hospital, Department of Internal Medicine, Division of Geriatrics, Pendik, Istanbul, 34662 , Turkey

2. Istanbul Medical School, Department of Internal Medicine, Division of Geriatrics, Istanbul University, Capa, 34093, Istanbul, Turkey

\begin{abstract}
Introduction: Sleep disorders are commonly under-diagnosed in the geriatric population. We aimed to determine the prevalence of sleep problems among older adults admitted to the geriatrics out-patient clinic.

Methods: Two hundred and three patients (136 female) older than 75 years of age were included in the study. Patients underwent comprehensive geriatric assessment, including identification of sleep problems using the Sleep Disturbance Scale, Rapid eye movement (REM) sleep behavior disorder (RBD) Single-Question Screen questionnaire (RBD1Q) and The Johns Hopkins Restless Leg Syndrome Severity Scale. Demographic and clinical data including age, sex, medications, comorbid diseases, body mass index and functional scores was noted.

Results: The mean age of the patients was $80.92 \pm 4.3$ years. $35.5 \%$ of the patients had findings of REM-SBD and $32.5 \%$ of the patients had restless legs syndrome. Ninety-seven percent of the patients answered 'yes' to at least one of the sleep disturbance scale questions. There was no significant difference between male and female groups.

Conclusion: We observed that sleep disorders were common among older adults. For this reason, the course and quality of sleep should be examined in all patients as a routine part of comprehensive geriatric assessment.
\end{abstract}

Keywords: Comprehensive geriatric assessment, older adults, sleep disorders.

DOI: https://dx.doi.org/10.4314/ahs.v17i2.18

Cite as: Tufan A, Ilhan B, Bahat G, Karan MA. An under-diagnosed geriatric syndrome: sleep disorders among older adults. Afri Health Sci. 2017;17(2): 436-444. bttps://dx.doi.org/10.4314/abs.v17i2.18

\section{Introduction}

Sleep is a naturally recurring state of mind and body characterized by altered consciousness, relatively inhibited sensory activity, and reduced interactions with surroundings. It effects mental, physiologic, and psychologic activities and is also effected by the ${ }^{1}$.

Sleep consists of two basic stages known as REM and non-REM cycles. REM stands for "rapid eye movement"
Corresponding author:
Asli Tufan,
Marmara University Hospital,
Department of Internal Medicine,
Division of Geriatrics, Pendik,
Istanbul, 34662, Turkey
Telephone: + 90216 4254545-6909
E-mail: aslitufan@yahoo.com

and non-REM stands for non eye movement. This cycle takes almost 90-100 minutes ${ }^{2}$.

Sleep patterns change with aging. Melatonin releasing decreases with age because of pineal gland calcification. Therefore the following changes occur in older people; sleep early and wake up early, frequent awakenings at night, decline in sleep time and in 'delta sleep' which is deep and the most restful form of sleep ${ }^{3,4}$.

Many forms of sleep disorders increase with age. Sleep disorders of older people are mostly overlooked and not detected unless questioned comprehensively.

Previous studies show that more than half of older people have insomnia ${ }^{5}$. Insomnia is a sleep disorder that is characterized by difficulty falling and/or staying asleep, waking up often during the night and having trouble going back to sleep, waking up too early in the morning, and feeling tired upon waking although patients have suitable conditions and enough time for sleep ${ }^{6}$. 
Rapid eye movement (REM) sleep behavior disorder (RBD) is a subgroup of parasomnia involving involuntary abnormal movements, behaviors, emotions, perceptions or dreams while sleeping. People appear to "act out their dreams," in which the exhibited behaviors mirror the content of the dreams, and the dream content often involves a chasing or attacking theme. Prodromal phase may take $20-25$ years acting mild or subclinic course (flailing, talking, wailing during sleep). It is more common in men and $>60$ years of age. It can be idiopatic or associated with central nervous system diseases ${ }^{7,8}$.

Sleep movement disorders include conditions that cause simple and stereotypic movements during or prior to sleep. These disorders can make it difficult to fall asleep or stay asleep, or to get restful sleep. Patients may be unaware or aware of such movements ${ }^{9}$. Few of typical subgroups are restless leg syndrome, periodic limb movements, and sleep leg cramps. It may be secondary to renal failure, folate and iron deficiencies, peripheral neuropathy, rheumatoid arthtritis, and fibromyalgia ${ }^{10}$.

Following conditions increasing with age may also cause sleep disorders: dementia, depression, delirium, gastroesophageal reflux, lung diseases, anxiety, fear of death, pain, nocturia, and medications ${ }^{11}$. Therefore clinicians should be aware of sleep disorders of older people and query them comprehensively. Insomnia may result in decline in cognition and physical performance, falls, physical dependence, and respiratory depression ${ }^{7,8}$.

In this study, we aimed to determine the prevalence of sleep disorders among older adults admitted to the geriatrics out-patient clinic in a university hospital .

\section{Methods \\ Subjects}

A total of 203 patients aged $>75$ years who were referred to the geriatric out-patient clinic between January 2014 and December 2014 were included.

All patients were informed about the study procedure and gave consent to participate in the study. Patients who received $<24$ for the Mini-Mental State Examination (MMSE) and/or did not agree to participate were not included in the study.

The study was conducted in accordance with the guidelines in the Declaration of Helsinki. Informed consent was obtained for all participants or the related conservators. The study was approved by the local ethics committee.

\section{Measurements}

Age, sex, number of chronically-used drugs (defined as the drugs used by the patient in a continuous manner, not only for a few prescriptions), number of chronic diseases, and functional scores were recorded by a geriatrician. Height and weight were measured then body mass index (BMI) was calculated as weight (kilograms) divided by height $^{2}$ (meters).

Functionality was evaluated using 6-item Katz activities of daily living (ADL) scores and 8-item Lawton instrumental activities of daily living (IADL) scores ${ }^{12,13}$. The scores for each item were determined as 1, 2, and 3 if the patient was totally dependent, partially dependent, and independent for performing the related activity, respectively. For ADL, 6, 7-12, and 13-18 points, and for IADL, 8, 9-16, and 17-24 points correspond to dependency, partial dependency, and independency, respectively.

The condition of sleep was questioned by asking about the following: "difficulty falling asleep,taking or being dependent on medication to help one sleep, sleep interrupted during the night, difficulty sleeping (falling/staying asleep) owing to moods or tension, difficulty sleeping owing to pain or itching, inability to return to sleep after waking at night, waking early or feeling tired, sleeping more than two hours during the day."The sleep disturbance scale had eight items, a score of two or more indicated caseness ${ }^{14}$.

REM sleep behavior disorder was examined through the RBD Single-Question Screen (RBD1Q) which consists of a single "yes-no" question: "Have you ever been told, or suspected yourself, that you seem to 'act out your dreams' while asleep (for example, punching, flailing your arms in the air, making running movements, etc.)?". The single-item design and good psychometric property render RBD1Q a good screening tool in clinical settings and large-scale epidemiological studies ${ }^{15}$.

Restless leg syndrome was evaluated through the following question: "Do you feel discomfort during some nights that causes an urge to move your legs?" If the answer was positive, the participant was asked to explain their discomfort by using The Johns Hopkins Restless Leg Severity Scale. According to this scale, "O" indicates no symptoms, " 1 " for symptoms during night, " 2 " for symptoms during evening and night, and " 3 " indicated symptoms present before 6 o'clock in the evening ${ }^{16}$. 


\section{Statistical analysis}

All data was entered into a database and verified by a second independent person. Descriptive statistics were generated for all study variables, including mean and standard deviation for normally distributed continuous variables, median for abnormally distributed variables and relative frequencies for categorical (qualitative) variables. The two groups were compared using paired Student's t-test or Mann-Whitney U tests when necessary. Chi-square test with Yates's correction and Fisher's exact test were used for $2 \times 2$ contingency tables when appropriate for non-numeric data. The results were evaluated in $95 \%$ confidence interval and at $\mathrm{p}<0.05$ level. The statistical analysis was performed using the statistical package IBM SPSS for Windows version 21 (IBM corporation, Armonk, NY, USA).

\section{Results}

The clinical characteristics of the subjects are summarized in Table 1. Sixty-seven (33\%) men and 136 (67\%) women were enrolled into the study. The mean age of the patients was $80.92 \pm 4.3$ years.

The mean body mass index (BMI) was $26.3 \pm 4.3 \mathrm{~kg} /$ $\mathrm{m}^{2}$ in the men, and $29.8 \pm 5.5 \mathrm{~kg} / \mathrm{m}^{2}$ in the women, and $28.7 \pm 5.4 \mathrm{~kg} / \mathrm{m}^{2}$ among all patients. The difference between men's and women's BMI was highly statistically significant $(\mathrm{p}=0.000)$.

The average number of medications used by the patients was $6.37 \pm 3.4(6.52 \pm 3.7$ in men, $6.29 \pm 3.2$ in women) $(\mathrm{p}=0.694)$.

The mean score of activities of daily living (ADL) was $16.4 \pm 2.4$ in the men and was $16.0 \pm 2.4$ in the women $(\mathrm{p}=0.176)$. The mean instrumental activities of daily living (IADL) score was 20.12 \pm 5.0 in the men and 18.96 \pm 5.6 in the women.

Table 1. General characteristics of the study population $(n=203)$

\begin{tabular}{|c|c|c|c|c|c|c|c|c|}
\hline \multirow{3}{*}{ Gender } & & \multicolumn{2}{|c|}{ Male } & \multicolumn{2}{|c|}{ Female } & \multicolumn{2}{|c|}{ Total } & \multirow[t]{3}{*}{$p$} \\
\hline & & \multirow{2}{*}{$\frac{\mathbf{n}}{67}$} & \multirow{2}{*}{$\begin{array}{l}\% \\
33\end{array}$} & \multicolumn{2}{|c|}{ n $\%$} & \multirow{2}{*}{\multicolumn{2}{|c|}{ n $\quad \%$}} & \\
\hline & & & & 136 & 67 & & & \\
\hline Age & $\begin{array}{l}76-85 \\
>85\end{array}$ & $\begin{array}{l}55 \\
12\end{array}$ & $\begin{array}{l}82.1 \\
17.9\end{array}$ & $\begin{array}{l}116 \\
20\end{array}$ & $\begin{array}{l}85.3 \\
14.7\end{array}$ & $\begin{array}{l}171 \\
32\end{array}$ & $\begin{array}{l}84.2 \\
15.8\end{array}$ & $p=0.684$ \\
\hline BMI $\left(\mathrm{kg} / \mathrm{m}^{2)}\right.$ & $\begin{array}{l}<23.9 \\
24.0-29.9 \\
>30,0\end{array}$ & $\begin{array}{l}23 \\
30 \\
14\end{array}$ & $\begin{array}{l}34.3 \\
44.8 \\
20.9\end{array}$ & $\begin{array}{l}13 \\
69 \\
54\end{array}$ & $\begin{array}{r}9.6 \\
50.7 \\
39.7\end{array}$ & $\begin{array}{l}36 \\
99 \\
68\end{array}$ & $\begin{array}{l}17.7 \\
48.8 \\
33.5\end{array}$ & $\mathrm{p}=0.000$ \\
\hline $\begin{array}{l}\text { Number of } \mathbf{C} \\
\text { Diseases }\end{array}$ & omorbid & $\begin{array}{l}0 \\
20 \\
31 \\
16\end{array}$ & $\begin{array}{r}0 \\
29.9 \\
46.3 \\
23.9\end{array}$ & $\begin{array}{r}2 \\
41 \\
72 \\
21\end{array}$ & $\begin{array}{r}1.5 \\
30.1 \\
52.9 \\
15.4\end{array}$ & $\begin{array}{l}2 \\
61 \\
103 \\
37\end{array}$ & $\begin{array}{r}1.0 \\
30.0 \\
50.7 \\
18.3\end{array}$ & $p=0.347$ \\
\hline ADL & $\begin{array}{c}\text { independent }(13-18) \\
\text { totally dependent }(0-6) \\
\text { partially dependent }(7-12)\end{array}$ & $\begin{array}{l}63 \\
2 \\
2\end{array}$ & $\begin{array}{r}94.0 \\
3.0 \\
3.0\end{array}$ & $\begin{array}{l}122 \\
2 \\
12\end{array}$ & $\begin{array}{r}89.7 \\
1.5 \\
8.8\end{array}$ & $\begin{array}{l}185 \\
4 \\
14\end{array}$ & $\begin{array}{r}91.1 \\
2.0 \\
6.9\end{array}$ & $\mathrm{p}=0.308$ \\
\hline IADL & $\begin{array}{l}\text { independent }(17-24) \\
\text { totally dependent }(0-8) \\
\text { partially dependent }(9-16)\end{array}$ & $\begin{array}{l}54 \\
3 \\
14.9\end{array}$ & $\begin{array}{c}80.6 \\
4.5 \\
10\end{array}$ & $\begin{array}{l}90 \\
7 \\
28.7\end{array}$ & $\begin{array}{c}66.2 \\
5.1 \\
39\end{array}$ & $\begin{array}{l}144 \\
10 \\
49\end{array}$ & $\begin{array}{r}70.9 \\
4.9 \\
24.1\end{array}$ & $\mathrm{p}=0.033$ \\
\hline Polypharmac & y ( $\geq 5$ medication/day) & 43 & 64.2 & 98 & 72.1 & 141 & 69.5 & $\mathrm{p}=0.252$ \\
\hline
\end{tabular}

(BMI: Body Mass Index, ADL: activities of daily living, IADL: instrumental activities of daily living)

The average number of chronic diseases was $4.7 \pm 2.1$ (4.9 \pm 2.3 in the men, $4.6 \pm 2.0$ in the women) $(p=0.347)$. Of the patients, $99 \%$ had at least one chronic disease. The most common co-morbidities were hypertension
(75.4\%), osteoporosis (40\%), hyperlipidemia (26.7\%), diabetes mellitus (DM) (24.6\%), and ischemic heart disease $(21.7 \%)$. Only three patients had sleep apnea and none were using sleep apnea tools (Table 2). 
Table 2. The comorbidities of the study population [n (\%)]

\begin{tabular}{|l|c|}
\hline Condition & number \% \\
\hline Hypertension & {$[\mathbf{n}(\mathbf{\%})]$} \\
Osteoporosis & $83(75.4)$ \\
Hyperlipidemia & $53(26.7)$ \\
Diabetes Mellitus & $50(24.6)$ \\
Ischemic heart disease & $43(21.7)$ \\
Chronic renal disease (GFR $<50 \mathrm{~mL} / \mathrm{min})$ & $32(15.8)$ \\
Dyspepsia & $30(14)$ \\
Benign Prostate Hypertrophy & $28(13.8)$ \\
Depression & $27(13)$ \\
Hypothyroidism & $24(11.8)$ \\
Cerebrovascular disease & $21(10.3)$ \\
Osteoarthritis & $18(8.9)$ \\
COPD & $13(7.4)$ \\
Iron deficiency anemia & $13(6.4)$ \\
Sleep apnea & $3(1.5)$ \\
\hline
\end{tabular}

COPD chronic obstructive pulmonary disease, GFR glomerular filtration rate

After condition of sleep was questioned, we discovered $18.7 \%$ took sleeping medication, and $56.7 \%$ woke up that $55.2 \%$ of the patients had 5-8 hours of sleep every involuntarily. Most of the $35.5 \%$ of patients who had day, $26.6 \%$ did not believe the duration of their sleep to difficulty falling asleep were women $(41.2 \%$ vs $23.9 \%$; be sufficient, 93.6\% woke up in the night at least once, $\mathrm{p}<0.05$ ) (Table 3). 
Table 3. Comparison of the sleep pattern by gender

\begin{tabular}{|c|c|c|c|c|c|c|c|}
\hline & \multicolumn{2}{|c|}{ Male } & $\begin{array}{l}\text { Fem } \\
\mathrm{n}\end{array}$ & & $\begin{array}{l}\text { Total } \\
\mathrm{n}\end{array}$ & $\%$ & $\mathrm{p}$ value \\
\hline Sleep duration 1-4 hours & 5 & 7.5 & 13 & 9.6 & 18 & 8.9 & $>0.05$ \\
\hline 5-8 hours & 37 & 55.2 & 75 & 55.1 & 112 & 55.2 & \\
\hline 9-12 hours & 23 & 34.3 & 44 & 32.4 & 67 & 33.0 & \\
\hline$>12$ hours & 2 & 3.0 & 4 & 2.9 & 6 & 3.0 & \\
\hline Any difficulties falling asleep? YES & 16 & 23.9 & 56 & 41.2 & 72 & 35.5 & $<0.05$ \\
\hline NO & 51 & 76.1 & 80 & 58.8 & 131 & 64.9 & \\
\hline Taking medication to sleep? YES & 10 & 14.9 & 28 & 20.6 & 38 & 18.7 & $>0.05$ \\
\hline NO & 57 & 85.1 & 108 & 79.4 & 165 & 81.3 & \\
\hline Involuntary waking early? YES & 33 & 49.3 & 82 & 60.3 & 115 & 56.7 & $>0.05$ \\
\hline NO & 34 & 50.7 & 54 & 39.7 & 88 & 43.3 & \\
\hline Sleep interruptions? & 63 & 94 & 127 & 93.4 & 190 & 93.6 & $>0.05$ \\
\hline NO & 4 & 6 & 9 & 6.6 & 13 & 6.4 & \\
\hline Is sleeping time enough ? & 52 & 77.6 & 97 & 71.3 & 149 & 73.4 & $>0.05$ \\
\hline NO & 15 & 22.4 & 39 & 28.7 & 54 & 26.6 & \\
\hline
\end{tabular}

$18.7 \%$ of the patients declared that they had taken a sleeping pill at least once in their lives. Of the sleeping pills taken, $60 \%$ were benzodiazepines and atypical antipsychotics.

Of the patients, $35.5 \%$ replied "yes" to the questions that aimed to detect REM sleep behavior disorder. There was no difference between the two sexes. (Table 4)

Regarding restless leg syndrome, $32.5 \%$ of the patients gave a positive reply to the questions about nighttime restlessness. There was no difference between the sexes. 
Table 4. Comparison of REM behaviour disorder and restless leg syndrome by gender

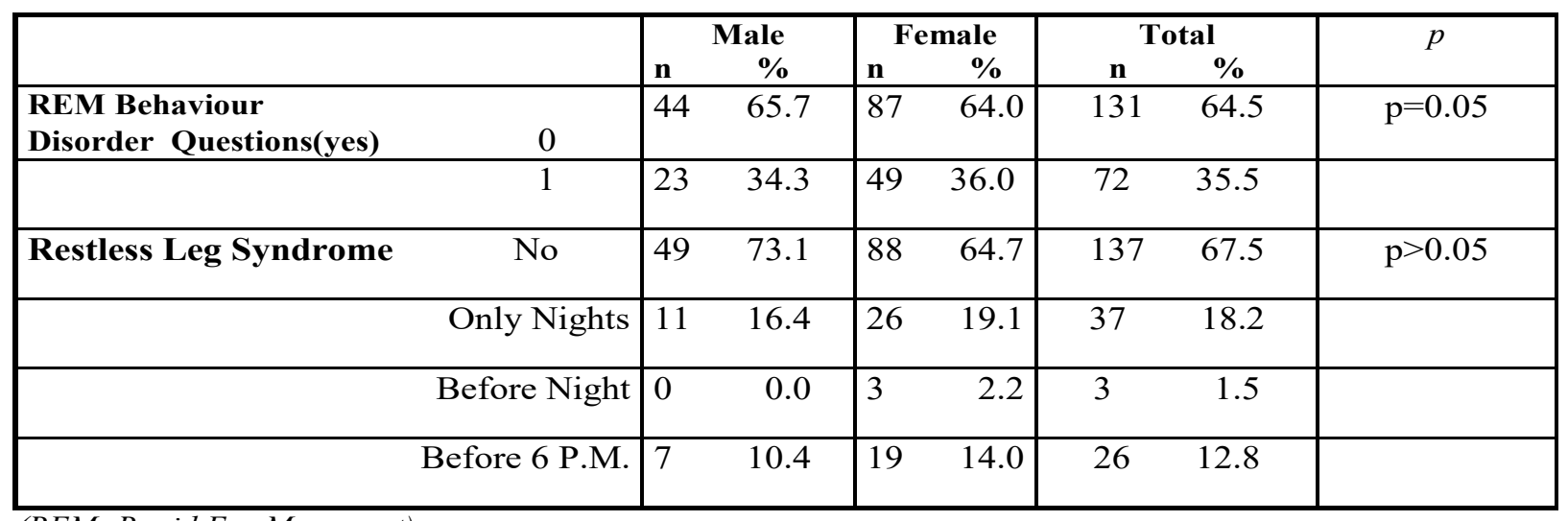

(REM: Rapid Eye Movement)

\section{Discussion}

Sleep disorders in the elderly are usually overlooked and mostly unidentified unless investigated thoroughly. They result in undesired consequences such as impairment in cognitive function, decreased physical performance, risk of falling,traffic accidents, respiratory depression, and physical dependence ${ }^{17-20}$.

Insomnia is defined as difficulty in falling or staying asleep or inability to wake up rested ${ }^{21}$. It is considered pathological in cases where it occurs despite ideal conditions for sleep and disrupts one's daily activities ${ }^{22}$. Kamel et al. suggested that more than $50 \%$ of people had insomnia ${ }^{23}$. Different studies from various countries showed that this rate varies between $30 \%$ and $60 \%{ }^{24-26}$. The annual incidence rate is reported to be $5 \%{ }^{27}$. Benbir et al. analyzed a total of 5021 people in their study of the Turkish adult population epidemiology of sleep disorders (TAPES). The authors demonstrated that the incidence of insomnia among the elderly (aged 65 years and older) was $13.9 \%{ }^{28}$. Overall, difficulty in falling asleep was reported to be experienced by $15-45 \%$ of the elderly, interrupted sleep by $20-65 \%$, waking up exceptionally early by $15-54 \%$, and inability to wake up rested was $10 \% 0^{29-30}$. Similar to the literature, in our study we discovered $35.5 \%$ had difficulty in falling asleep, $26.6 \%$ did not believe they had enough sleep, and $93.6 \%$ woke at least once during the night, and $56.7 \%$ woke up involuntarily early in the morning.In our study, the $35.5 \%$ who had difficulty in falling asleep were mostly women. Insomnia is more common in elderly women than men. An epidemiologic study analyzed patients aged 70 years or older and showed approximately $35 \%$ of the women had medium and severe insomnia and $13 \%$ had insomnia ${ }^{31}$. This difference may be related with changes in hormone levels of women during the post-menopausal period. The decrease in estrogen after the beginning of post-menopausal period is believed to be the reason why women experience difficulties with sleep more often ${ }^{32}$.

Older people's accompanying physical diseases may contribute to the development of insomnia. It has been found that the frequency of insomnia and other sleep disorders increases as the population of people aged 65 years or older acquire more accompanying physical diseases. Chronic pain related to osteoarthritis, cancer or diabetes, chronic obstructive respiratory disease, congestive heart failure, and neurologic diseases are considered the most relevant diseases to insomnia ${ }^{33-35}$. In our study, 99\% of the patients had at least one chronic disease.

REM sleep behavior disorder is more common in men. Its incidence increases with age $e^{36,37}$. In our study, 35.5\% of the patients answered "yes" to questions that were meant to detect REM sleep behavior disorder. However, there was no difference in terms of the participants' sex. Restless leg syndrome is the feeling of restlessness sensed in the legs, which prevents sleep ${ }^{38,39}$. Patients feel inclined to move or massage extremities or get up and walk in order to cope with this feeling. As a result,it takes longer to fall asleep, quality of sleep decreases, and productivity is reduced due to sleepiness. The general incidence in the population is approximately $10 \%$. Although this disease is more common in women, its incidence increases with age,both in women and men ${ }^{40,41}$. In our study, $32.5 \%$ of the patients responded positively to the question about restless leg syndrome.

Of the patients in our study, $6.4 \%$ had been diagnosed as having iron deficiency and $15.8 \%$ chronic renal fail- 
ure. The fact that the elderly are more likely to experience restless leg syndrome may be because of the increase in the incidence of iron deficiency and renal diseases with age and the decrease in the amount of dopamine.

$18.7 \%$ of the patients declared that they had taken a sleeping pill at least once in their lives, most of which $(60 \%)$ were benzodiazepines and atypical anti-psychotics. However, these medications should be used carefully and treatment should be individualized, taking into account the potential adverse effects (such as excessive sedation, cognitive disorder, delirium, agitation, confusion, risk of falling and fractures, balance problems, performance loss that affect daily life, and addiction), especially to hypnotic drugs (both benzodiazepines and non-benzodiazepines) in older patients ${ }^{42-44}$.

Anti-psychotics alone can increase the incidence of sudden death, increased cerebrovascular events, and cardiac pathologies, and therefore are not recommended for sleep treatment ${ }^{45}$.

\section{Limitations}

This study has a number of limitations. The cross-sectional design prevented investigating causality. It was conducted in a single geriatric center; however, patients who were admitted to our hospital represent a large variety of geriatric individuals from different cities because it is a referral center. Also we did not include patients with dementia because of the reliability of the answers about sleep cycle.

\section{Conclusion}

Sleep disorders are more common in older people compared with all the other age groups. For this reason, the course and quality of sleep should be examined in all patients as a routine part of comprehensive geriatric assessment. Sleep disorders should be treated through changes in lifestyle and pharmacologic approaches .

\section{Learning points}

- Sleep disorders are more common in older people compared with all the other age groups.

- Sleep should be examined in all patients as a routine part of comprehensive geriatric assessment.

\section{Conflict of interest}

The authors report no conflict of interest. The authors alone were responsible for the content and writing of the article. None of the authors of this manuscript have any financial or personal relationships with other people or organizations that could inappropriately influence (bias) their work. None of the co-authors have direct or indirect conflicts of interest, financial or otherwise, relating to the subject of our report. There is no role of sponsorship.

\section{Disclosure statement:}

The authors have no potential conflicts of interest to disclose.

\section{Acknowledgement:}

Authors' contributions

AT contributed to design and conduct of the study, data analysis and interpretation, review and approval of the manuscript. BI, GB. contributed to data analysis and interpretation, and approval of the manuscript. MAK contributed in reviewing and approval of the manuscript.

\section{References}

1. Ohayon MM, Carskadon MA, Guilleminault C, Vitiello MV. Meta-analysis of quantitative sleep parameters from childhood to old age in healthy individuals: developing normative sleep values across the human lifespan. Sleep. 2004 Nov1;27(7):1255-73.

2. Foley D, Ancoli-Israel S, Britz P, Walsh J. Sleep disturbances and chronic disease in older adults: results of the 2003 National Sleep Foundation Sleep in America Survey. J Psychosom Res. 2004 May; 56(5):497-502.

3. Blazer DG, Hays JC, Foley DJ. Sleep complaints in older adults: a racial comparison. J Gerontol A Biol Sci Med Sci. 1995 Sep;50(5):M280-4.

4. Ohayon MM. Epidemiology of insomnia: what we know and what we still need to learn. Sleep Med Rev. 2002 Apr;6(2):97-111.

5. Foley DJ, Monjan AA, Brown SL, Simonsick EM, Wallace RB, Blazer DG. Sleep complaints among elderly persons: an epidemiologic study of three communities. Sleep 1995;18:425-32 PubMed .

6. Sukying C, Bhokakul V, Udomsubpayakul U. An epidemiological study on insomnia in an elderly Thai population. J Med Assoc Thai. 2003 Apr;86(4):316-24.

7. Boeve BF, Silber MH, Saper CB, Ferman TJ, Dickson DW, Parisi JE, et al. Pathophysiology of REM sleep behaviour disorder and relevance to neurodegenerative disease. Brain. 2007 Nov;130(Pt 11):2770-88.

8. Boeve BF, Dickson DW, Olson EJ, Shepard JW, Silber $\mathrm{MH}$, Ferman TJ, et al. Insights into REM sleep behavior disorder pathophysiology in brainstem-predominant 
Lewy body disease. Sleep Med. 2007 Jan;8(1):60-4.

9. Reading P. Things that go bump in the night: diagnosing sleep-related movement disorders without a sleep laboratory. J R Coll Physicians Edinb. 2014;44(1):57-63.

10. Hening W, Allen RP, Tenzer P, Winkelman JW. Restless legs syndrome: demographics, presentation, and differential diagnosis. Geriatrics. 2007 Sep;62(9):26-9.

11. Swift CG, Shapiro CM. ABC of sleep disorders. Sleep and sleep problems in elderly people. BMJ. 1993 May 29;306(6890):1468-71.

12. Cho YC, Alessi CA, Cho M. The association between chronic illness and functional change among participants in Comprehensive Geriatric Assessment Program. Am Geriatr Soc;1998;46: 677-682 PubMed .

13. Lawton MP, Moss M, Fulcomer M, Kleban MH. A research and service oriented multilevel assessment instrument. J Gerontol. 1982;37:91-9 PubMed .

14. Livingston G, Blizard B, Mann A. Does sleep disturbance predict depression in elderly people? A study in inner London. Br J Gen Pract. 1993;43:445-448. PubMed 15. Postuma RB, Arnulf I, $\operatorname{Hog}$ B, Iranzo A, Miyamoto T, Dauvilliers Y, et al. A single-question screen for Rapid Eye Movement Sleep Behavior Disorder: a multicentre validation study. Mov Dis 2012;27:913-6. PubMed 16. Allen RP, Earley CJ. Validation of the Johns Hopkins Restless Legs Severity Scale. Sleep Medicine. 2001; 2, 239242 PubMed

17. Stone KL, Ewing SK, Lui LY, Ensrud KE, Ancoli-Israel S, Bauer DC, et al. Self-reported sleep and nap habits and risk of falls and fractures in older women: the study of osteoporotic fractures. I Am Geriatr Soc 2006; 54: 1177 83 PubMed .

18. Avidan AY, Fries BE, James ML, Szafara KL, Wright GT, Chervin RD. Insomnia and hypnotic use, recorded in the minimum data set, as predictors of falls and hip fractures in Michigan nursing homes. J Am Geriatr Soc 2005; 53: 955-62 PubMed .

19. Stone KL, Ancoli-Israel S, Blackwell T, Ensrud KE, Cauley JA, Redline S, et al. Actigraphy-measured sleep characteristics and risk of falls in older women. Arch Intern Med 2008; 168: 1768-75 PubMed .

20. Dew MA, Hoch CC, Buysse DJ, Monk TH, Begley AE, Houck PR, et al. Healthy older adults' sleep predicts all cause mortality at 4 to 19 years of follow-up. Psychosom Med 2003; 65: 63-73 PubMed .

21. Benca RM. Insomnia. In: Avidan AY, Zee PC (eds).
Handbook of Sleep Medicine. Philadelphia: Lippincott Williams and Wilkins, 2006: 36-69.

22. Kaymak SU, Peker S, Cankurtaran ES, Soygur AH. Sleep Problems in the Geriatric Population. I Acad Geriatr 2010;2:61-70 PubMed

23. Kamel NS, Gammack JK. Insomnia in the elderly: cause, approach, and treatment. Am J Med 2006;119(6):463-9. PubMed

24. Sukying C, Bhokakul V, Udomsubpayakul U. An epidemiological study on insomnia in an elderly Thai population. J Med Assoc Thai 2003;86(4):316-24. PubMed 25. Schubert CR, Cruickshanks KJ, Dalton DS, Klein BE, Klein R, Nondahl DM. Prevalence of sleep problems and quality of life in an older population. Sleep 2002; 25(8):889-93. PubMed

26. Maggi S, Langlois JA, Minicuci N, Grigoletto F, Pavan M, Foley DJ, et al. Sleep complaints in community-dwelling older persons: prevalence, associated factors, and reported causes. J Am Geriatr Soc 1998;46(2):161-8. PubMed

27. Foley DJ, Monjan A, Simonsick EM, Wallace RB, Blazer DG. Incidence and remission of insomnia among elderly adults: an epidemiologic study of 6,800 persons over three years. Sleep 1999;22 Suppl 2:S366-72.

28. Benbir G, Demir AU, Aksu M, Ardic S, Firat H, Itil O, et al. Prevalence of insomnia and its clinical correlates in a general population in Turkey. Psychiatry Clin Neurosci. 2014 Nov 11.

29. Espiritu JR. Aging-related sleep changes. Clin Geriatr Med 2008; 24: 1-14 PubMed .

30. Ohayon MM. Epidemiology of insomnia: what we know and what we still need to learn. Sleep Med Rev 2002; 6: 97-111 PubMed

31. Byles JE, Mishra GD, Harris MA. The experience of insomnia among older women. Sleep 2005;28(8):972 PubMed -9.

32. Moe KE. Reproductive hormones, aging, and sleep. Semin Repord Endocrinol 1999; 17: 339-48.

33. Quan SF, Katz R, Olson J, Bonekat W, Enright PL, Young T, et al. Factors associated with incidence and persistence of symptoms of disturbed sleep in elderly cohort: the Cardiovascular Health Study. Am J Med Sci 2005; 329: 163-72 PubMed .

34. Garc1'a-Borreguero D, Larrosa O, Bravo M. Parkinson's disease and sleep. Sleep Med Rev 2003; 7: 115-29 PubMed . 
35. Semla TP, Beizer JL, Higbee MD. Geriatric Dosage Handbook. 12 $2^{\text {th }}$ ed. Hudson, OH: Lexi-Comp, 2007

36. Olson EJ, Boeve BF, Silber MH. Rapid eye movement sleep behavior disorder: demographic, clinical and laboratory findings in 93 cases. Brain 2000; 123: 331-9 PubMed . 37. Sforza E, Krieger J, Petiau C. REM sleep behavior disorder: clinical and physiopathological findings. Sleep Med Rev 1997; 1: 57-69 PubMed

38. American Academy of Sleep Medicine. International Classification of Sleep Disorders. Diagnostic and Coding Manual. $2^{\text {nd }}$ ed. Westchester, IL: American Academy of Sleep Medicine, 2005.

39. National Heart, Lung, and Blood Institute. Restless legs syndrome: detection and management in primary care. NHLBI- Accessed July 27, 2008

40. Bixler EO, Kales A, Vela-Bueno A, Jacoby JA, Scarone $\mathrm{S}$, Soldatos CR. Nocturnal myoclonus and noctur- nal myoclonic activity in normal population. Res Common Chem Pathol Pharmacol 1982; 36: 129-40.

41. Piani A, Brotini S, Dolso P, Budai R, Gigli GL. Sleep disturbances in elderly: a subjective evaluation over 65 . Arch Gerontol Geriatr Suppl 2004; 9: 325-31. 42. Gray SL, LaCroix AZ, Hanlon JT, Penninx BW, Blough DK, Leveille SG, et al. Benzodiazepine use and physical disability in community-dwelling older adults. $J$ Am Geriatr Soc 2006;54(2):224-30. PubMed 43. Cumming RG, Le Couteur DG. Benzodiazepines and risk of hip fractures in older people: a review of the evidence. CNS Drugs 2003;17(11):825-37. PubMed 44. Kudoh A, Takase H, Takahira Y, Takazawa T. Postoperative confusion increases in elderly long-term benzodiazepine users. Anesth Analg 2004;99(6):1674-8. PubMed 45. Kuehn BM. FDA warns anti-psychotic drugs may be risky for elderly. JAMA 2005;293(20): 2462 PubMed . 